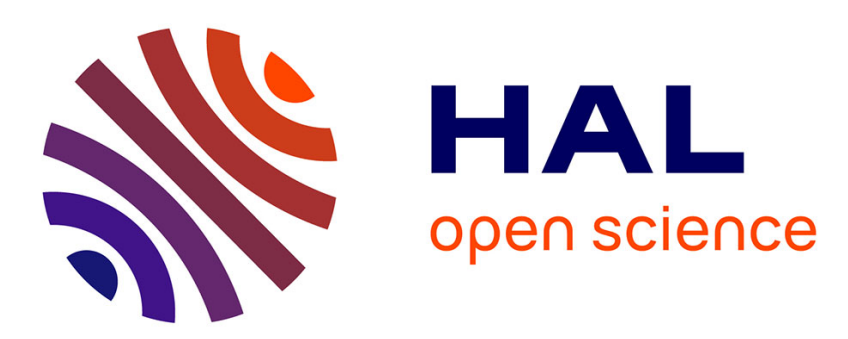

\title{
The gut in iron homeostasis: role of HIF-2 under normal and pathological conditions.
}

Maria Mastrogiannaki, Pavle Matak, Carole Peyssonnaux

\section{To cite this version:}

Maria Mastrogiannaki, Pavle Matak, Carole Peyssonnaux. The gut in iron homeostasis: role of HIF-2 under normal and pathological conditions.. Blood, 2013, 122 (6), pp.885-92. 10.1182/blood-2012-11427765 . inserm- 01068507

\section{HAL Id: inserm-01068507 https://www.hal.inserm.fr/inserm-01068507}

Submitted on 25 Sep 2014

HAL is a multi-disciplinary open access archive for the deposit and dissemination of scientific research documents, whether they are published or not. The documents may come from teaching and research institutions in France or abroad, or from public or private research centers.
L'archive ouverte pluridisciplinaire HAL, est destinée au dépôt et à la diffusion de documents scientifiques de niveau recherche, publiés ou non, émanant des établissements d'enseignement et de recherche français ou étrangers, des laboratoires publics ou privés. 


\title{
The gut in iron homeostasis: role of HIF-2 under normal and pathological conditions
}

\author{
Maria Mastrogiannaki, ${ }^{1-3}$ Pavle Matak, ${ }^{1-3}$ and Carole Peyssonnaux ${ }^{1-3}$ \\ ${ }^{1}$ Institut National de la Santé et de la Recherche Médicale (INSERM), U1016, Institut Cochin, Paris, France; ${ }^{2}$ Centre National de la Recherche Scientifique, \\ UMR8104, Paris, France; and ${ }^{3}$ Université Paris Descartes, Sorbonne Paris Cité, Paris, France
}

\begin{abstract}
Although earlier, seminal studies demonstrated that the gut per se has the intrinsic ability to regulate the rates of iron absorption, the spotlight in the past decade has been placed on the systemic regulation of iron homeostasis by the hepatic hormone hepcidin and the molecular mechanisms that regulate its
\end{abstract}

expression. Recently, however, attention has returned to the gut based on the finding that hypoxia inducible factor-2 (HIF-2 $\alpha$ ) regulates the expression of key genes that contribute to iron absorption. Here we review the current understanding of the molecular mechanisms that regulate iron homeostasis in the gut by focusing on the role of HIF-2 under physiological steady-state conditions and in the pathogenesis of iron-related diseases. We also discuss implications for adapting HIF-2-based therapeutic strategies in iron-related pathological conditions. (Blood. 2013;122(6):885-892)

\section{Introduction}

Iron $(\mathrm{Fe})$ is an essential nutrient required in many cellular biosynthetic and metabolic processes such as heme and sulfur-iron cluster biosynthesis, oxygen transport, mitochondrial respiration, and DNA replication. ${ }^{1}$ The body of a healthy human male contains $\sim 4 \mathrm{~g}$ of total iron, which is in a dynamic equilibrium between different tissues: $1 \mathrm{~g}$ is predominantly stored in hepatocytes, whereas $65 \%$ to $80 \%$ of total iron traffics in a closed circuit in which erythrophagocytosis of senescent red blood cells by reticuloendothelial macrophages in the spleen enables iron to be returned to the bone marrow for incorporation into new erythrocytes. Approximately $1 \mathrm{mg}$ of dietary iron is absorbed daily at the proximal duodenum, a process that is essential in order to replace daily losses due to limited blood losses, desquamation, and so forth. ${ }^{2}$ Excess iron accumulation and the resulting production of reactive oxygen species through the Fenton/ Haber Weiss reaction are involved in the pathogenesis of ironoverload-related diseases including hereditary hemochromatosis $(\mathrm{HH})$ and $\beta$-thalassemia.

Iron absorption is increased during iron deficiency and decreased upon iron loading. ${ }^{2}$ This inverse relationship depends on a network of signals, which reflect systemic body iron requirements and the interaction of these signals with the enterocyte iron sensing and transport machinery. Iron homeostasis is regulated systemically by the hormone hepcidin, a 25 -aminoacid peptide produced mainly by the hepatocytes. Hepcidin expression is increased by iron loading and inflammatory signals and is attenuated by iron deficiency, anemia, increased erythropoietic activity, and hypoxia. ${ }^{3}$ Hepcidin inhibits iron absorption and iron recycling by binding to the only known iron exporter, ferroportin (FPN). ${ }^{4}$ Recent advances in the understanding of the regulation of hepcidin expression and the mechanism of hepcidin action have been detailed elsewhere. ${ }^{3}$

Here, we review current knowledge regarding the roles of hypoxia inducible factor-2 (HIF-2) and iron regulatory proteins 1 (IRP1) and 2 (IRP2) in the molecular circuitry that regulates iron absorption by enterocytes. We also discuss recent findings demonstrating the importance of IRP1-dependent regulation of HIF-2 in the regulation of iron homeostasis and implications in the context of iron-related pathophysiological conditions.

\section{Key molecules regulating iron homeostasis in the gut}

Dietary iron is broadly classified into 2 categories based on chemical form. The majority of iron is nonheme iron, which is present in most foods, including cereal, vegetables, and meat. It is found in ferritin (Ft) and other proteins, as well as several nonprotein-bound forms. ${ }^{5}$ Iron that is present in heme is mainly found in meat.

The solubility of ferric salts or nonheme iron is highly dependent on a variety of intraluminal parameters, including $\mathrm{pH} .{ }^{6}$ In the presence of reductive factors or reductases, ferric iron $\left(\mathrm{Fe}^{3+}\right)$ is reduced to the ferrous $\left(\mathrm{Fe}^{2+}\right)$ form at the brush border membrane. Duodenal cytochrome b561 (DCYTB), a diheme-containing and ascorbatedependent ferric enzyme, has been proposed to mediate this reductive event in the duodenum. ${ }^{7}$ While Dcytb knockout mice display no overt defects in iron homeostasis when subjected to iron-rich or irondeficient diets, ${ }^{8}$ they have less nonheme iron in the spleen and significantly lower reticulocyte mean corpuscular hemoglobin when compared with control mice. ${ }^{9}$ Ferric reductases belonging to the Steap family also have been proposed to act at the brush border membrane. ${ }^{10}$

$\mathrm{Fe}^{2+}$ can be transported via divalent metal-ion transporter 1 (DMT1/NRAMP2). ${ }^{11}$ DMT1 is a proton-coupled metal transporter of a broad range of divalent ions, although $\mathrm{Fe}^{2+}$ is its principal physiological substrate. The importance of duodenal DMT1 in $\mathrm{Fe}^{2+}$ transport is underscored by the anemic phenotype of Dmt1 intestinal knockout mutants. ${ }^{12}$ Mutations of DMT1 in humans result in hypochromic microcytic anemia that may ${ }^{13}$ or may not ${ }^{14}$ be accompanied by massive hepatic iron overload.

Iron absorbed by mature enterocytes is either stored in $\mathrm{Ft}$ or exported across the basolateral enterocyte membrane into the plasma by FPN. ${ }^{15} \mathrm{Ft}$ is a globular protein composed of both $\mathrm{H}(\mathrm{FtH})$ and 
L (FtL) subunits. FtH possesses ferroxidase activity and has been shown, in addition to its iron storage function, to play an active role in iron export. $^{16}$

Accordingly, Fpn deletion in the murine intestine results in enterocyte iron overload and neonatal lethality. ${ }^{17}$ FPN exports $\mathrm{Fe}^{2+}$; the release of iron from FPN is coupled to the actions of copper-dependent ferroxidases, primarily the transmembrane protein hephaestin (HEPH) ${ }^{18} \mathrm{HEPH}$ catalyzes the oxidation of $\mathrm{Fe}^{+2}$ to $\mathrm{Fe}^{+3}$, which is subsequently bound to transferrin. Disruption of HEPH activity (eg, due to copper deficiency or mutation, as in the sex-linked anemia mouse) results in iron sequestration in enterocytes, confirming its key role in iron export across the enterocyte basolateral membrane. ${ }^{19}$

Free heme is highly insoluble due to its hydrophobic porphyrin ring. However, heme can be complexed to a number of chelators (including arginate and albumin) and preferentially absorbed in duodenum as the intestinal $\mathrm{pH} 5.5$ to 6 favors its solubility. ${ }^{20} \mathrm{Heme}$ carrier protein 1 has been proposed as an intestinal heme transporter, but in vivo studies indicate that heme carrier protein 1 functions predominantly as a folate transporter. ${ }^{21}$ Therefore, the mechanism of heme uptake by enterocytes remains unresolved. HRG-1 is another heme transporter, ${ }^{22}$ for which an essential role for macrophage hemeiron recycling has been recently demonstrated. ${ }^{23}$ HRG-1 may potentially function as a heme transporter in the intestine. Heme is catabolized by heme-oxygenase into $\mathrm{Fe}^{2+}$ bilirubin and carbon monoxide. Feline leukemia virus subgroup $\mathrm{C}$ cellular receptor is a transmembrane heme exporter that plays a key role in erythropoiesis by exporting excess heme from maturing erythroblasts in humans. ${ }^{24}$ Feline leukemia virus subgroup C cellular receptor is also abundantly expressed in the duodenum, but its specific role in heme export from enterocytes has not been addressed.

\section{Systemic vs local regulation of iron absorption in the gut}

Iron absorption is increased under conditions of iron deficiency, increased erythropoietic drive, and hypoxia and is decreased by iron loading and inflammation. Expression of the key proteins involved in iron absorption is controlled at multiple levels: transcriptional, posttranscriptional, and posttranslational. The different steps of the iron absorption process may be subject to distinct cell-autonomous mechanisms and/or systemic regulation by hepcidin.

The majority of the body's daily iron consumption is used to meet the needs of erythropoiesis. In settings of increased erythropoietic demand, intestinal iron absorption increases to meet the marrow's needs for additional iron. Increased erythropoietic activity in the bone marrow is observed in different forms of anemia ranging from irondeficiency anemia to hereditary forms characterized by ineffective erythropoiesis, such as $\beta$-thalassemia. Prolonged exposure to a hypoxic environment in humans, as well as experimental hypoxia and anemia induced by phlebotomy/hemolysis in mouse models, is also characterized by an increased erythropoietic demand and results in an increase in iron absorption rates. ${ }^{25-27}$

\section{Systemic regulation of iron absorption by hepcidin}

Increased iron absorption correlates with elevated expression of DMT1, DCYTB, and FPN at the messenger RNA (mRNA) and protein level. ${ }^{7,11,28,29}$ Hepatic hepcidin expression is inversely correlated with the duodenal expression of iron transporters and iron absorption rates in various mouse models of hepcidin overexpression and deficiency. ${ }^{30-32}$ The established view is that plasma hepcidin inhibits iron efflux into plasma by directly binding to and thereby inducing the degradation of FPN, which is located on enterocytes and macrophages. However, data on the precise molecular actions of hepcidin on FPN in the gut are less clear. ${ }^{29,33-35}$

Some reports have suggested that hepcidin also may reduce iron absorption by decreasing the expression of enterocyte DMT1, either at the transcription level ${ }^{34}$ or through ubiquitin-dependent proteasomal degradation. ${ }^{35}$ The Nedd4 interacting protein 1 (NDFP1) and 2 (NDFP2) adaptor proteins have been reported to regulate DMT1 in vitro via ubiquitination by WW domain containing E3 ubiquitin protein ligase 2 (WWP2) and neural precursor cell expressed developmentally down-regulated 4-like E3 ubiquitin protein ligase (NEDD4L or NEDD4-2) in Chinese hamster ovary cells. ${ }^{36}$ The involvement of this NDFIPs-WWP2 pathway in the hepcidinmediated degradation of DMT1 remains to be demonstrated.

\section{Local regulation of iron absorption in enterocytes}

Although it is widely recognized that low liver hepcidin expression contributes to the upregulated expression of iron transporters during iron deficiency, in vitro evidence has suggested that the upregulated expression of iron transporters that occurs following exposure to desferroxamine, an iron chelator, occurs in a cell-autonomous manner. ${ }^{28}$ Cell-autonomous regulation of duodenal iron absorption in response to hypoxia has also been well documented. Early experimental evidence supported the notion that acute hypoxia affects apical iron uptake independently of systemic cues such as erythropoietic drive or hepcidin levels: increased apical iron uptake was observed in rats as early as 6 to 8 hours after initiation of hypoxia. ${ }^{37,38}$ This early induction precedes changes in circulating iron levels or erythropoiesis ${ }^{37,38}$ or a decrease in hepcidin occurring only after at least 24 hours of hypoxia in mice ${ }^{39}$ and in humans. ${ }^{40,41}$ In addition, this hypoxic response increased iron absorption but was independent of dietary or mucosal iron status. ${ }^{42}$

Although the effect of increased erythropoiesis on iron absorption has generally been attributed to the strong downregulation of hepcidin expression, a direct effect of erythropoietin (EPO) on duodenal enterocytes has been recently proposed. Srai et $\mathrm{al}^{43}$ suggested that EPO acts directly on duodenal enterocytes through its receptor EPO-R to upregulate expression of iron transporters, based on findings in a nephrectomized rat model of chronic renal failure. Whether this mechanism is relevant in human pathological conditions characterized by ineffective erythropoiesis (such as $\beta$-thalassemia), or in murine experimental models of hypoxia or anemia characterized by high erythropoietic demand and iron absorption rates, remains to be established.

While iron deficiency and hypoxia promote iron absorption, oral administration of large doses of iron attenuates the subsequent absorption of smaller doses of iron administered hours later. This effect has been attributed to decreases in transcript and protein levels of both DCYTB and DMT1, which occur as early as 6 hours post iron administration, but not to changes in the expression of FPN or $\mathrm{HEPH}^{44}$ These findings indicate that local enterocyte iron levels can directly regulate the apical membrane phase of iron transport.

\section{Transcriptional regulation by HIF-2}

The transcriptional regulation of genes involved in apical iron uptake and mucosal iron transfer was largely unknown until the recent discovery of the involvement of HIF-2 transcription factor in this process. The HIF transcription factors are central mediators of cellular adaptation to hypoxia. ${ }^{45} \mathrm{HIF}$ is a heterodimer, and its expression is 


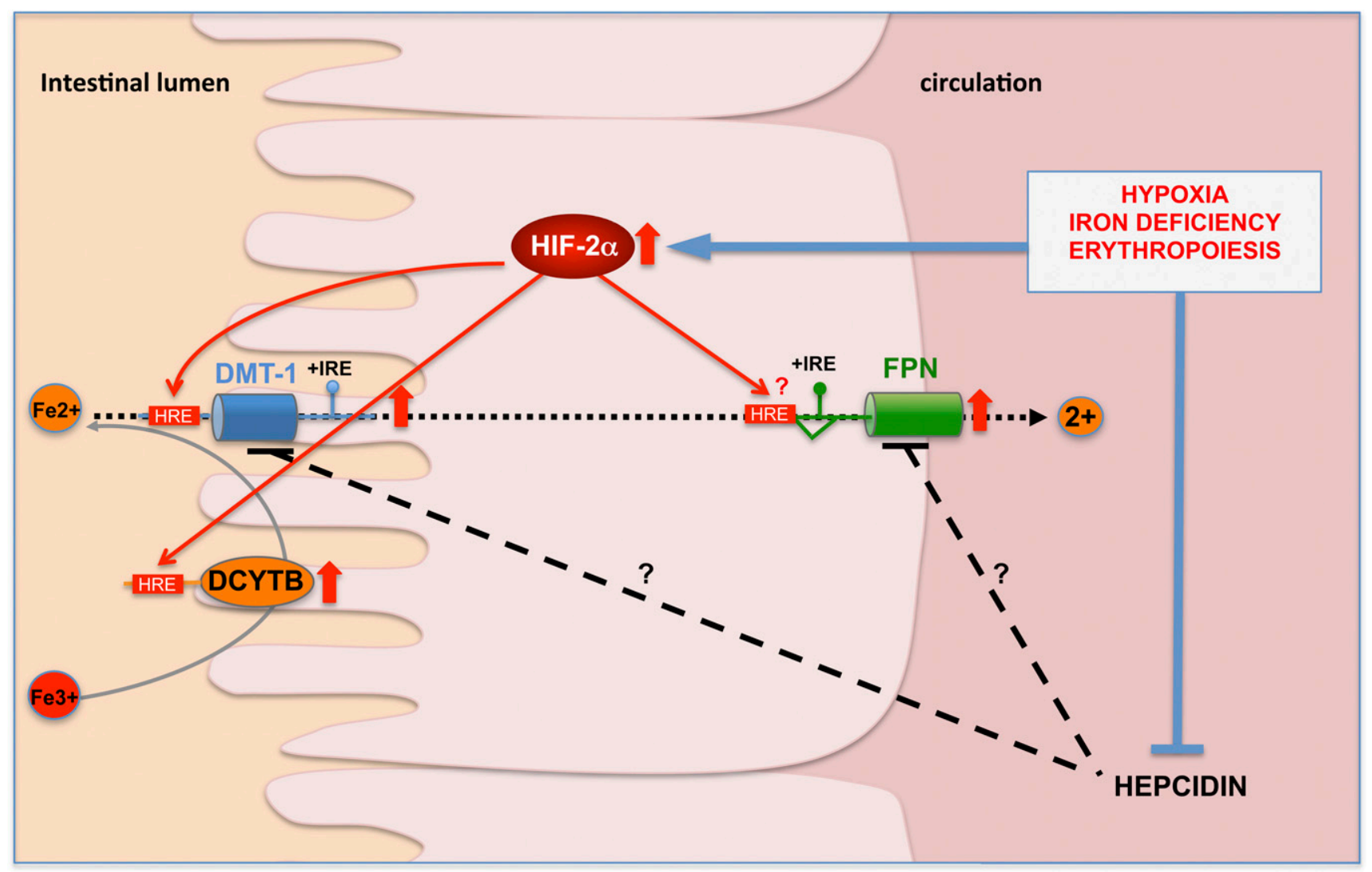

Figure 1. HIF-2 transcriptionally regulates the expression of key genes involved in iron transport. Under conditions of iron deficiency, hypoxia, or increased erythropoietic drive, HIF-2 is stabilized in the duodenal enterocyte and transcriptionally upregulates the expression of DMT1 + iron responsive element (IRE), DCYTB, and FPN. This leads to increased expression of DMT1 and DCYTB at the apical brush border membrane and FPN at the basal membrane. ${ }^{29,52,53,58}$ The direct binding of HIF-2 to consensus HRE elements in the regulatory regions of the promoters has been shown for DCYTB and DMT1. At the systemic level, hepatic hepcidin is repressed, preventing its inhibitory action on duodenal iron absorption.

principally regulated by oxygen. The HIF heterodimer consists of 2 helix-loop-helix proteins: an $\alpha$-regulatory subunit, which is the oxygen- and iron-responsive component, and the $\beta$-subunit, also known as the aryl hydrocarbon receptor nuclear translocator, which is constitutively expressed. Three regulatory HIF subunits have been cloned and named HIF- $1 \alpha$, HIF- $2 \alpha$, and HIF-3 $\alpha$. To date, HIF- $1 \alpha$ has been the most extensively studied. In the presence of oxygen, the hydroxylation of HIF- $\alpha$ at conserved proline residues within the oxygen-dependent degradation domain is the rate-limiting step for subsequent HIF- $\alpha$ protein degradation and is catalyzed by prolyl-4hydroxylase domain enzymes (PHDs). ${ }^{46}$ Three PHD isoforms exist in mammals and are encoded by different genes: PHD1 (also known as egg laying defective gene [EGL] 9 homolog [EGLN] 2 or HIF prolyl hydroxylase $[\mathrm{HPH}] 3$ ), PHD2 (EGLN1 or HPH2), and PHD3 (EGLN3 or HPH1). PHDs are iron- and 2-oxoglutarate-dependent dioxygenases utilizing $\mathrm{O}_{2}$ as a substrate, 2-oxoglutarate as a cosubstrate, and iron $\left(\mathrm{Fe}^{2+}\right)$ and ascorbate as cofactors. The 4-hydroxyprolines are subsequently recognized by the protein von Hippel-Lindau (pVHL) E3 ubiquitin ligase, which targets HIF- $\alpha$ for degradation by the $26 \mathrm{~S}$ proteasome through polyubiquitination by the E3ubiquitin-ligase complex containing elongin B and C, cullin-2, and rbx $1 .{ }^{47}$

Factor inhibiting HIF is another 2-oxoglutarate-dependent dioxygenase that hydroxylates a conserved asparagine residue within the C-terminal transactivation domain of HIF1- $\alpha$ and HIF2- $\alpha .{ }^{48}$ Asparagine hydroxylation impairs interaction of $\mathrm{HIF}-\alpha$ with the transcriptional coactivators p300 and CREB-binding protein and therefore inhibits transcriptional activity. ${ }^{49} \mathrm{HIF}-1 \alpha$ is probably the preferentially targeted $\alpha$-isoform. ${ }^{49}$ When $\mathrm{O}_{2}$ is scarce, or under iron-deficient conditions, the activities of PHD and factor inhibiting HIF are inhibited, thus enabling HIF- $\alpha$ to escape degradation and translocate to the nucleus where it dimerizes with the constitutive subunit HIF-1 $\beta$ /aryl hydrocarbon receptor nuclear translocator. The HIF heterodimer then binds within the DNA regulatory promoter or enhancer regions of target genes at specific locations termed hypoxia response elements (HREs) and recruits transcriptional coactivators, p300/CREB-binding protein, to activate transcription. ${ }^{50}$ The core HRE consists of the sequence RCGTG $(R=A / G$, most often $\mathrm{G})$ and is surrounded by binding sites for additional transcriptional factors and coactivators. ${ }^{50}$

Several links between regulation of HIF stability and iron homeostasis have been identified, ${ }^{51}$ and more recently, HIF-2 has emerged as an important "local" regulator of intestinal iron absorption that directly trans-activates the expression of iron transporter genes in enterocytes ${ }^{29,52,53}$ (Figure 1). Indeed, mice lacking HIF-2 $\alpha$ in the intestinal epithelium exhibited significant decreases in the duodenal levels of Dmt1, Dcytb and FPN mRNAs, effects that were not compensated by HIF-1. ${ }^{52}$ This decrease in the expression of genes involved in both apical and basolateral iron transport was associated with a significant reduction in plasma and liver iron content, and a marked decrease in hepatic hepcidin expression, demonstrating a pivotal role of HIF-2 in steady-state regulation of iron absorption. Although HIF-2 intestinal knockout mice did not show striking differences in the morphology of intestinal villi when compared with control mice, a potential effect of HIF-2 on enterocyte survival, proliferation, or shedding has not been systematically investigated ${ }^{53,54}$ 
and remains to be addressed in future studies of the role of HIF-2 in intestinal function.

The differential target gene specificity of HIF- $2 \alpha$ vs HIF- $1 \alpha$ in the duodenum may be due to interaction of the HIF- $\alpha N$-terminal sequence with additional transcription factors, as has previously been suggested. ${ }^{55}$ Orthologs of Sp6 transcription factors may possibly act in cooperation with HIF-2 to increase iron absorption. ${ }^{56}$ Further, certain physiological features of the intestinal epithelium may explain the phenotype of HIF- $2 \alpha$ intestinal knockout mice at the basal level. The gastrointestinal tract has a unique tissue oxygenation profile under steady-state conditions. While the epithelium is in a relatively hypoxic state, the subepithelial mucosa is highly vascularized, and meal ingestion is known to increase the mucosal blood flow. Reduced blood flow in the villus microvasculature during the fasting period could thus result in a relatively hypoxic state of the duodenal enterocytes, which would stabilize HIF-2 $\alpha$, therefore potentiating the expression of DMT1 and $D C Y T B$ in order to increase apical iron uptake during digestion of a subsequent meal. Alternatively, other mechanisms could affect local HIF-2 $\alpha$ levels in the duodenal enterocytes, such as intraluminal $\mathrm{pH}$ levels. In human subjects, intraluminal duodenal $\mathrm{pH}$ fluctuates from 4.0 during meals to below 2.0 during the fasting period. Iron absorption of inorganic iron is influenced by $\mathrm{pH}^{6}{ }^{6}$ Given the links between $\mathrm{pH}$ regulation and HIF signaling, ${ }^{57}$ it is possible that low intraluminal $\mathrm{pH}$ may potentiate HIF- $2 \alpha$ stabilization. Additionally, upregulation of duodenal HIF- $2 \alpha$ is likely to occur at the protein level through diminished PHD activity in the hypoxic microvilli. Importantly, mice developing severe anemia and tissue hypoxia in response to phenyladrazine treatment do not exhibit changes in duodenal HIF$2 \alpha$ mRNA levels. ${ }^{58}$ Increased duodenal HIF- $2 \alpha$ protein stabilization has been shown to mediate the upregulation of Dmt1 and Dcytb mRNAs in mice fed an iron-deficient diet. ${ }^{52,53}$ A biphasic regulation of duodenal FPN has been reported during iron deficiency in mice, in which HIF-2 is essential in the acute regulation of iron export but dispensable in the chronic phase. ${ }^{29}$ As iron absorption rates are higher in younger animals, it is also conceivable that HIF-2 might be more important during periods of postnatal growth than in adults. HIF-2 protein levels are also stabilized in other conditions of high iron demand, such as hypoxia ${ }^{59}$ or phlebotomy ${ }^{58}$ (Figure 1). Altogether, these findings reveal an important role for HIF-2 in the iron- and oxygen-dependent regulation of iron absorption.

\section{Posttranscriptional regulation by the IRPs: a new IRP1/HIF-2 axis}

Posttranscriptional regulation of iron homeostasis genes in response to intracellular iron levels is mediated by IRPs, IRP1 and IRP2, which bind to IREs found in the $5^{\prime}$ or $3^{\prime}$ untranslated regions (UTRs) of target mRNAs. ${ }^{60}$ IRP1 and IRP2 protein abundance and IRE-binding activity are regulated by different mechanisms. ${ }^{61}$ IRP1 does not show detectable IRE-binding activity in the majority of tissues under physiological conditions, but rather is expressed in the form of a cytosolic aconitase. By contrast, the protein abundance of IRP2 is regulated by F-box and leucine-rich repeat protein 5, an iron- and oxygen-binding hemerythrin domain adaptor protein that recruits the SKP1-CUL1-F-box E3 ubiquitin ligase complex to promote IRP2 proteasomal degradation under iron-replete conditions. ${ }^{62}$ High IRP-binding activity in response to low intracellular iron levels results in translational repression of mRNAs that contain an IRE in their $5^{\prime}$ UTR (such as $F p n, F t H$, and $F t L$ ) or promotes mRNA stability if bound to mRNAs that contain an IRE in $3^{\prime}$ UTR (as in the case of Dmt1). Dmt1 is present in different isoforms, and those transcript isoforms that contain an IRE predominate in the proximal intestine. Although activation of IRPs by iron deficiency would normally be expected to repress translation of FPN, duodenal FPN levels are increased in iron-deficient animals. ${ }^{15}$ Importantly, Zhang et al $^{63}$ showed that an alternative Fpn mRNA lacking the 5' UTR IRE motif (Fpn-IRE) is preferentially expressed in the duodenum, which could explain how enterocytes circumvent repression of FPN expression by IRE/IRP machinery. Mice carrying a deletion for both IRP1 and IRP2 in the intestinal epithelium present with decreased DMT1 and transferrin receptor 1 and increased $\mathrm{FtH}$ and FtL protein levels, and they manifest malabsorption and villus structure disorganization associated with perinatal lethality. ${ }^{64}$ However, $\operatorname{Irp} 2^{-/-}$and $\operatorname{Irp} 1^{-/-}$mice are both viable but present different overt phenotypes. More specifically, mice with Irp2 deletion in the intestinal epithelium present with iron retention in the duodenal enterocytes, suggesting that IRP2 plays a cell-autonomous role in the intestine and also that IRP1 and IRP2 are partly redundant in the intestine. ${ }^{65,66}$ Furthermore, tissue-specific $\operatorname{Irp1} 1^{-1-}$ and/or $\operatorname{Irp} 2^{-1-}$ knockout mouse models have demonstrated that IRP 2 is the major regulator of iron homeostasis in vivo, responding to dietary iron deficiency and hypoxia. ${ }^{60}$ A $5^{\prime}$ UTR IRE in the Hif $2 \alpha$ mRNA has been characterized in vitro and may serve as an additional point of HIF-2 regulation. ${ }^{67}$ Sanchez et al ${ }^{67}$ proposed that HIF-2 translation may be enhanced in the presence of adequate levels of iron. In rats, hepatic HIF- $2 \alpha$ has been shown to be translationally repressed in response to dietary iron deficiency compatible with a role for the IRE/IRP system in this process. ${ }^{68}$

Two recent studies have demonstrated that translational regulation of HIF- $2 \alpha$ synthesis by IRP1 in the kidney is critical for controlling erythropoiesis. ${ }^{69,70}$ Ghosh et $\mathrm{al}^{70}$ showed that $\operatorname{Irpl}^{-1-}$ mice develop pulmonary hypertension and polycythemia, a phenotype that is exacerbated in response to an iron-deficient diet and is caused by excessive EPO production resulting from the absence of translational repression of Hif- $2 \alpha$ mRNA in the kidney. Interestingly, the authors also showed that secretion of the known HIF target endothelin-1 is highly upregulated in pulmonary endothelial cells isolated from Irp1 $1^{-1-}$ mice compared with controls. Anderson et $\mathrm{al}^{69}$ further demonstrated that HIF-2 transcriptional activity is increased in the duodenum of $\mathrm{Irpl}^{-1-}$ mice, as indicated by the increased mRNA expression of Dmt1+IRE, Dcytb, and Fpn mRNAs, as well as other HIF-2 target genes. Moreover, Galy et $\mathrm{al}^{71}$ recently reported that IRPs regulate apical iron uptake by controlling FPN and DMT1 through HIF-2. They further showed that IRP deficiency in the adult mouse intestinal epithelium promotes a Ft-mediated "mucosal block."

As IRP activity is increased in the duodenum in response to iron deficiency, ${ }^{72}$ it might be hypothesized that Hif- $2 \alpha$ is translationally repressed by IRP1. However, increased HIF-2 $\alpha$ protein levels have been reported in the duodenum of iron-deficient mice. ${ }^{53} \mathrm{~A}$ possible explanation might be that during iron deficiency, the effects of IRP1 on Hif- $2 \alpha$ mRNA translation are counteracted by the dominant stabilization of HIF- $2 \alpha$ at the protein level, due to the decreased activities of PHDs (Figure 2). Moreover, IRP1 has been shown to decrease in hypoxia. ${ }^{73}$ As the duodenum is hypoxic, even at basal level, the decrease in IRP1 would amplify the impact of PHD-mediated regulation of HIF- $2 \alpha$ accumulation. By contrast, high intracellular iron would prevent the translational repression of Hif- $2 \alpha$ by IRP1 but potentially increase the activity of PHDs (Figure 2). However, models of intestinal iron overload coupled with systemic anemia indicate that elevated iron levels do not have a pronounced effect on HIF-2 per se and that systemic anemia/hypoxia is the predominant regulator of HIF-2. ${ }^{74}$ It would be interesting to examine these hypotheses more 


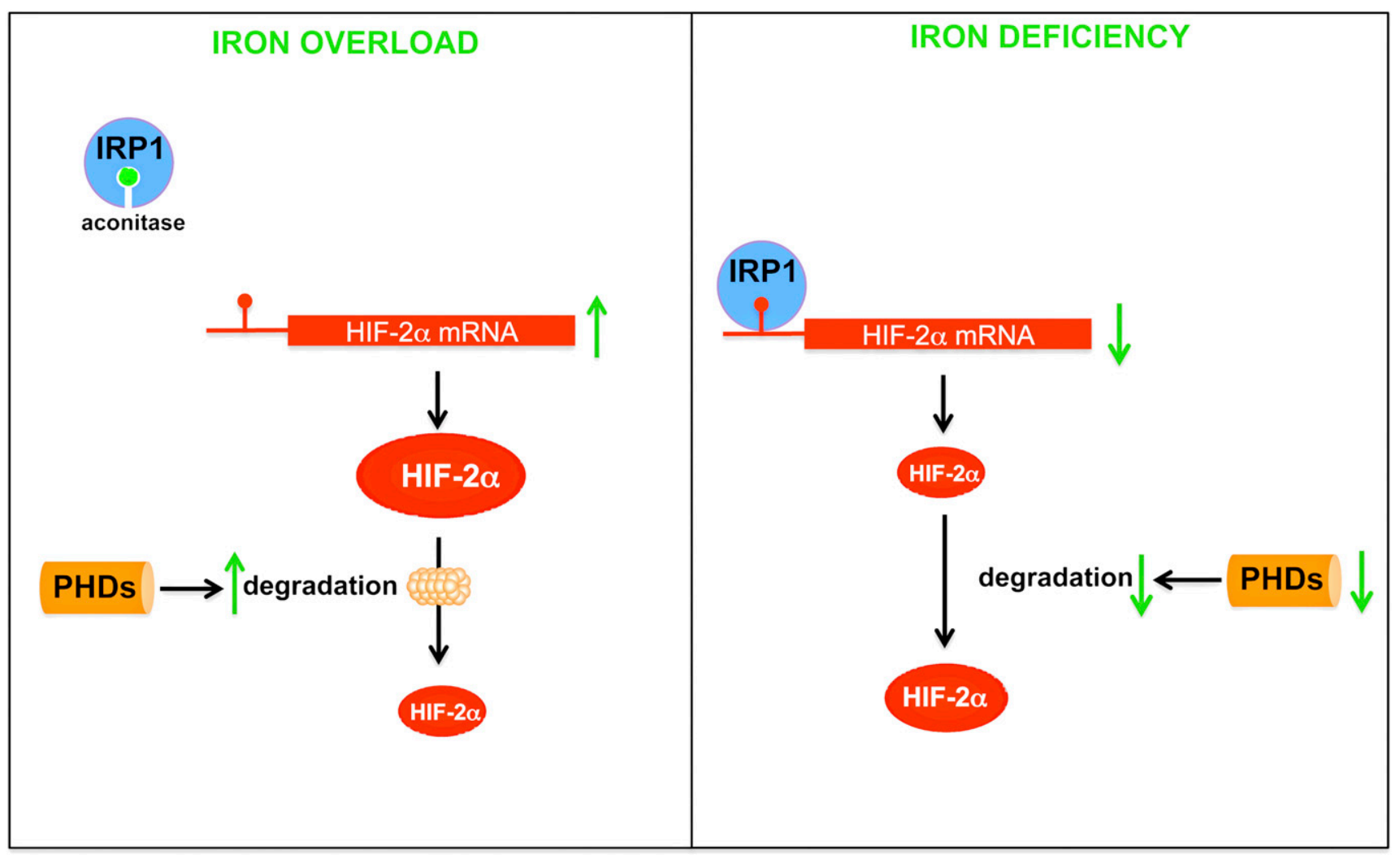

Figure 2. Schematic of HIF-2 regulation in response to cellular iron deficiency and overload in duodenal enterocytes. When cytosolic iron levels are elevated, IRP1 incorporates an iron-sulfur cluster, which interferes with the ability of IRP1 to bind IRE. This promotes translation of HIF-2 mRNA but also increases the degradation of HIF-2 mediated by the PHDs. When cytosolic iron levels are low, IRP1 binds to IRE in the 5'-UTR of HIF-2 mRNA, blocking HIF-2 translation. However, decreased activity of PHDs prevents the degradation of HIF-2 by the proteasome.

specifically in mice with inducible deletion of Irp1 or Irp2 in the intestinal epithelium. Further studies addressing these questions may provide evidence for nonredundant roles of IRPs in the duodenum and their importance in integrating systemic physiological signals in vivo.

\section{HIF-2: implications for iron-related disorders}

\section{Inflammation}

Iron absorption is diminished during inflammatory conditions. Eventually, a decrease in serum iron limits iron availability to erythropoiesis and contributes to the anemia of inflammation (also called anemia of chronic disease [ACD]). ${ }^{75}$ Hypoferremia is mainly due to iron sequestration in macrophages of the reticuloendothelial system.

Hepatic hepcidin expression is markedly induced during infection and inflammation by cytokines (including interleukin [IL] 1 and IL-6), ${ }^{76}$ and urinary hepcidin levels are elevated in patients with chronic inflammatory diseases. ${ }^{77}$ IL- 6 signals through binding to the IL-6 receptor and activates hepcidin transcription by binding of phosphorylated Signal Transducer and Activator of Transcription (STAT) to conserved sequence elements in the hepcidin promoter. The resulting hepcidin elevation is believed to play a major role in the pathogenesis of ACD. ${ }^{77}$ These features are reproducible in transgenic mouse models that overexpress hepcidin ${ }^{78,79}$ and in mice injected with the synthetic hepcidin peptide. ${ }^{80}$ The role of hepcidin in the anemia of inflammation has been detailed elsewhere. ${ }^{75}$

Inflammation also seems to have a direct effect on iron absorption. Tumor necrosis factor $\alpha$ treatment decreased intestinal iron absorption both in vitro and in vivo. ${ }^{81,82}$ In the early inflammatory response, tumor necrosis factor appears to mediate hypoferremia independently of hepcidin. ${ }^{83}$ The hepcidin-independent effect of inflammation on duodenal iron absorption awaits further investigation.

The mechanisms operating in the intestine to decrease iron absorption during inflammation have been poorly studied at the cellular level. Importantly, HIF-1 $\alpha$ has been shown to play a crucial role in the regulation of epithelial barrier function of the mucosa in mouse models characterized by intestinal inflammation. ${ }^{84}$ However, the role of HIF- $2 \alpha$ during intestinal inflammation has not yet been addressed. Interestingly, nitric oxide (NO), an important mediator of inflammation, has been shown to stimulate the IRE-binding activity of IRP1 in macrophages. ${ }^{85}$ Although this mechanism has not been validated in enterocytes, it is possible that NO-mediated translational repression of HIF-2 could contribute to the ability of inflammation to decrease in iron absorption.

\section{Polycythemia/ineffective erythropoiesis}

Erythrocytosis is caused by an exacerbated proliferation of erythrocyte progenitors in the bone marrow leading to an absolute increase in circulating red cell mass. Individuals who are exposed to high-altitude hypoxia develop erythrocytosis and an accompanying increase in iron absorption when compared with native residents of high altitude or to individuals living at sea level. ${ }^{86}$ Interestingly, HIF-2 $\alpha$ and PHD2 polymorphisms are present at high frequencies in human populations living in the Tibetan or Andean plateaus and are associated with lower values of hemoglobin than in individuals living in other altitudes. ${ }^{87,88}$ This implies a selective advantage in these individuals in comparison with normal individuals developing polycythemia in high altitudes. 
Increased but defective production of erythroblasts in the bone marrow, a process known as ineffective erythropoieis, is a hallmark of $\beta$-thalassemia and other dyserythropoietic anemias. ${ }^{89} \beta$-thalassemic patients and mouse models present inappropriately low expression of hepcidin relative to hepatic iron stores and high iron absorption rates. ${ }^{90}$ The molecular mechanism(s) by which the erythropoietic drive promotes hepcidin suppression during normal and stress erythropoiesis has not been fully elucidated so far. Possible regulators of hepcidin expression that have been proposed include changes in transferrin saturation, increased release of soluble molecules like growth differentiation factor 15 and twisted gastrulation homolog 1 from erythroblasts, and a direct effect of EPO on hepatocytes. ${ }^{91}$ Whether growth differentiation factor 15 or twisted gastrulation homolog 1 are upregulated in the gut in these conditions and whether they directly regulate iron absorption has not been examined.

Transfusion and pharmacologic chelation are the current treatments for patients with iron-loading anemias. However, both increased iron absorption and repetitive transfusions contribute to the massive organ iron load that leads to lethal complications. Anderson et $\mathrm{al}^{58}$ recently showed that intestinal HIF-2 is essential for efficient erythropoiesis. It would be of interest to explore whether intestinal HIF-2 contributes to iron absorption and iron overload observed in $\beta$-thalassemic patients.

\section{Hereditary hemochromatosis}

$\mathrm{HH}$ is an autosomal recessive genetic disorder characterized by iron overload in the liver and other parenchyma. HH is caused by mutations in genes encoding signaling molecules that regulate hepcidin expression in response to iron, namely, HFE, TfR2, and HFE2, or mutations in the hepcidin gene (HAMP) itself. The age of onset and clinical phenotype varies depending on the particular gene that is mutated. ${ }^{92}$ Another hereditary iron overload disorder (termed FPN disease) is caused by autosomal dominant mutations in the FPN gene that impair hepcidin binding or alter FPN localization. ${ }^{93}$

In regard to HFE-associated $\mathrm{HH}$, different mutations have been identified; however, their penetrance is variable, and HFE homozygotes show phenotypic heterogeneity that ranges from complete absence of disease to severe iron overload in liver and pancreas leading to complications such as hepatic steatosis, hepatocellular carcinoma, and diabetes. As previously mentioned, the HIF-2 transcription factor is crucial for the regulation of iron homeostasis by regulating the expression of DMT1 and DCYTB in the duodenum. ${ }^{52}$ Moreover, HIF- $2 \alpha$ stabilization in the intestinal epithelium is sufficient to augment expression levels of DMT1, DCYTB, and FPN and leads to hepatic iron overload. ${ }^{29,53}$ As previously mentioned, high expression levels of duodenal Dmt1, Dcytb, and Fpn mRNA correlate with high iron absorption rates in various models characterized by low hepcidin expression. Importantly, deletion of intestinal Hif- $2 \alpha$ in hepcidin knockout mice alleviates iron overload in the liver and pancreas by decreasing the expression of the duodenal DMT1, DCYTB, and FPN. ${ }^{54}$ These findings highlight the importance of HIF-2 in the transcriptional upregulation of genes involved in iron absorption in the context of hepcidin deficiency and suggest that HIF-2 could contribute to chronic iron accumulation in humans with HH. Recently, we showed that hepatic HIF- $2 \alpha$ is dispensable for the homeostatic response to iron deficiency, but genetic stabilization of HIF- $2 \alpha$ due to hepatic loss of VHL mediates a radical decrease in hepcidin expression that occurs in response to increased erythropoietic activity. ${ }^{54}$ Moreover, hepatic HIF-2 $\alpha$ stabilization in the context of VHL deficiency leads to the development of hepatic steatosis and highly angiogenic tumors in mice. ${ }^{94}$ It has been previously proposed that DMT1 ${ }^{95}$ and
DCYTB,${ }^{96} 2$ HIF-2 target genes, could act as genetic modifiers in HFE hemochromatosis. Therefore, whether polymorphic variation in HIF-2 $\alpha$ itself contributes to the phenotypic heterogeneity of HFE-related hemochromatosis patients developing severe clinical features (steatosis and cancer) vs milder phenotypes would be of interest.

\section{Potential of the use of HIF-2 modulators in the treatment of iron-related diseases}

Although the role of HIF-2 in the pathogenesis of HFE or other forms of hemochromatosis in humans remains to be established, the previously discussed findings provide proof of concept that HIF-2 inhibitors could be employed therapeutically in patients with $\mathrm{HH}$ in combination with conventional phlebotomy. Increased iron absorption is also believed to contribute to iron loading in thalassemias and sideroblastic anemia, in addition to that caused by successive blood transfusions. ${ }^{90}$ Therefore, HIF-2 inhibitors might also prove beneficial for these patients by inhibiting both inefficient erythropoiesis and iron absorption. Currently, 1 study has identified a class of chemical compounds that inhibit HIF-2 $\alpha$ translation by an IRP1dependent mechanism, ${ }^{97}$ but the pharmacokinetic properties and inhibitory potential of these compounds in vivo have not yet been determined. The recent demonstration of the critical role of the IRP-HIF-2 axis in intestinal iron absorption ${ }^{69,70}$ may encourage the evaluation of these HIF-2 inhibitors in vivo.

Finally, prolyl-hydroxylase inhibitors (PHIs) represent a promising potential alternative treatment for anemia. ${ }^{98,99}$ PHIs might be particularly advantageous in patients with anemia of renal failure, who are currently treated with intravenous/subcutaneous injections of recombinant EPO or related erythropoiesis-stimulating agents. PHIs improved hematologic parameters in a mouse model of chronic renal insufficiency by inducing hepatic Epo expression. ${ }^{100}$ However, the safety profile of PHIs and their ultimate efficacy in inducing the stabilization of both HIF-1 and HIF-2 in patients remain to be determined. Given the dual roles of HIF-2 in the regulation of iron absorption and EPO expression, PHIs or other compounds that specifically stabilize HIF-2 may represent possible therapeutic strategies for patients with iron-deficiency anemia or ACD.

\section{Acknowledgments}

The authors thank Sophie Vaulont (Institut Cochin) and Karin Finberg (Duke University) for critical reading of the manuscript.

\section{Authorship}

Contribution: M.M., P.M., and C.P. contributed to the writing of the manuscript.

Conflict-of-interest disclosure: The authors declare no competing financial interests.

The current affiliation for M.M. is Centre for Stem Cells \& Regenerative Medicine, Division of Genetics \& Molecular Medicine, King's College London School of Medicine, London, United Kingdom.

The current affiliation for P.M. is Department of Pharmacology and Cancer Biology, Duke University, Duke University Medical Center, Durham, NC.

Correspondence: Carole Peyssonnaux, INSERM, U1016, Institut Cochin, Faculté de Médecine Cochin Port Royal, 24, rue du Faubourg Saint Jacques, Paris, 75014, France; e-mail: carole.peyssonnaux@ inserm.fr. 


\section{References}

1. Andrews NC. Forging a field: the golden age of iron biology. Blood. 2008;112(2):219-230.

2. Anderson GJ, Darshan D, Wilkins SJ, Frazer DM. Regulation of systemic iron homeostasis: how the body responds to changes in iron demand. Biometals. 2007;20(3-4):665-674.

3. Ganz T, Nemeth E. Hepcidin and iron homeostasis. Biochim Biophys Acta. 2012; 1823(9):1434-1443.

4. Nemeth E, Tuttle MS, Powelson J, et al. Hepcidin regulates cellular iron efflux by binding to ferroportin and inducing its internalization. Science. 2004;306(5704):2090-2093.

5. Sharp PA. Intestinal iron absorption: regulation by dietary \& systemic factors. Int J Vitam Nutr Res. 2010;80(4-5):231-242.

6. Miret S, Simpson RJ, McKie AT. Physiology and molecular biology of dietary iron absorption. Annu Rev Nutr. 2003;23:283-301.

7. McKie AT, Barrow D, Latunde-Dada GO, et al An iron-regulated ferric reductase associated with the absorption of dietary iron. Science. 2001;291(5509):1755-1759.

8. Gunshin H, Starr CN, Direnzo C, et al. Cybrd1 (duodenal cytochrome $b$ ) is not necessary for dietary iron absorption in mice. Blood. 2005 106(8):2879-2883.

9. Choi J, Masaratana P, Latunde-Dada GO, Arno M, Simpson RJ, McKie AT. Duodenal reductase activity and spleen iron stores are reduced and erythropoiesis is abnormal in Dcytb knockout mice exposed to hypoxic conditions. J Nutr. 2012;142(11):1929-1934.

10. Knutson MD. Steap proteins: implications for iron and copper metabolism. Nutr Rev. 2007;65(7): 335-340.

11. Gunshin $\mathrm{H}$, Mackenzie B, Berger UV, et al. Cloning and characterization of a mammalian proton-coupled metal-ion transporter. Nature. 1997;388(6641):482-488.

12. Gunshin $\mathrm{H}$, Fujiwara $\mathrm{Y}$, Custodio AO, Direnzo $\mathrm{C}$, Robine S, Andrews NC. Slc11a2 is required for intestinal iron absorption and erythropoiesis but dispensable in placenta and liver. $J$ Clin Invest. 2005;115(5):1258-1266.

13. Iolascon A, d'Apolito M, Servedio V, Cimmino F, Piga A, Camaschella C. Microcytic anemia and hepatic iron overload in a child with compound heterozygous mutations in DMT1 (SCL11A2). Blood. 2006;107(1):349-354.

14. Blanco E, Kannengiesser C, Grandchamp B Tasso M, Beaumont C. Not all DMT1 mutations lead to iron overload. Blood Cells Mol Dis. 2009; 43(2):199-201.

15. McKie AT, Marciani P, Rolfs A, et al. A novel duodenal iron-regulated transporter, IREG1, implicated in the basolateral transfer of iron to the circulation. Mol Cell. 2000;5(2):299-309.

16. Vanoaica L, Darshan D, Richman L, Schümann $\mathrm{K}$, Kühn LC. Intestinal ferritin $\mathrm{H}$ is required for an accurate control of iron absorption. Cell Metab. 2010;12(3):273-282.

17. Donovan A, Lima CA, Pinkus JL, et al. The iron exporter ferroportin/Slc40a1 is essential for iron homeostasis. Cell Metab. 2005;1(3):191-200.

18. Yeh KY, Yeh M, Mims L, Glass J. Iron feeding induces ferroportin 1 and hephaestin migration and interaction in rat duodenal epithelium. $A m$ Physiol Gastrointest Liver Physiol. 2009;296(1): G55-G65.

19. Chen H, Huang G, Su T, et al. Decreased hephaestin activity in the intestine of copper-deficient mice causes systemic iron deficiency. J Nutr. 2006;136(5):1236-1241.
20. Conrad ME, Umbreit JN. Pathways of iron absorption. Blood Cells Mol Dis. 2002;29(3) 336-355.

21. Qiu A, Jansen M, Sakaris A, et al. Identification of an intestinal folate transporter and the molecular basis for hereditary folate malabsorption. Cell. 2006;127(5):917-928.

22. Yanatori I, Tabuchi M, Kawai Y, Yasui Y, Akagi $R$, Kishi F. Heme and non-heme iron transporters in non-polarized and polarized cells. BMC Cell Biol. 2010;11:39.

23. White $C$, Yuan $X$, Schmidt PJ, et al. HRG1 is essential for heme transport from the phagolysosome of macrophages during erythrophagocytosis. Cell Metab. 2013;17(2): 261-270.

24. Quigley JG, Yang Z, Worthington MT, et al. Identification of a human heme exporter that is essential for erythropoiesis. Cell. 2004;118(6): 757-766.

25. Faura J, Ramos J, Reynafarje C, English E, Finne P, Finch CA. Effect of altitude on erythropoiesis. Blood. 1969;33(5):668-676.

26. Latunde-Dada GO, Vulpe CD, Anderson GJ, Simpson RJ, McKie AT. Tissue-specific changes in iron metabolism genes in mice following phenylhydrazine-induced haemolysis. Biochim Biophys Acta. 2004;1690(2):169-176.

27. Leung PS, Srai SK, Mascarenhas M, Churchill LJ, Debnam ES. Increased duodenal iron uptake and transfer in a rat model of chronic hypoxia is accompanied by reduced hepcidin expression. Gut. 2005;54(10):1391-1395

28. Zoller H, Theurl I, Koch R, Kaser A, Weiss G. Mechanisms of iron mediated regulation of the duodenal iron transporters divalent metal transporter 1 and ferroportin 1. Blood Cells $\mathrm{Mol}$ Dis. 2002;29(3):488-497.

29. Taylor M, Qu A, Anderson ER, et al. Hypoxiainducible factor- $2 \alpha$ mediates the adaptive increase of intestinal ferroportin during iron deficiency in mice. Gastroenterology. 2011; 140(7):2044-2055.

30. Lesbordes-Brion JC, Viatte L, Bennoun M, et al. Targeted disruption of the hepcidin 1 gene results in severe hemochromatosis. Blood. 2006; 108(4):1402-1405.

31. Frazer DM, Wilkins SJ, Becker EM, et al. Hepcidin expression inversely correlates with the expression of duodenal iron transporters and iron absorption in rats. Gastroenterology. 2002; 123(3):835-844

32. Viatte L, Lesbordes-Brion JC, Lou DQ, et al. Deregulation of proteins involved in iron metabolism in hepcidin-deficient mice. Blood. 2005;105(12):4861-4864.

33. Chaston $\mathrm{T}$, Chung B, Mascarenhas $\mathrm{M}$, et al Evidence for differential effects of hepcidin in macrophages and intestinal epithelial cells. Gut. 2008;57(3):374-382.

34. Mena NP, Esparza A, Tapia V, Valdés $P$, Núñez MT. Hepcidin inhibits apical iron uptake in intestinal cells. Am J Physiol Gastrointest Liver Physiol. 2008;294(1):G192-G198.

35. Brasse-Lagnel C, Karim Z, Letteron P, Bekri S, Bado A, Beaumont C. Intestinal DMT1 cotransporter is down-regulated by hepcidin via proteasome internalization and degradation. Gastroenterology. 2011;140(4):1261-1271.e1.

36. Foot NJ, Dalton HE, Shearwin-Whyatt LM, et al. Regulation of the divalent metal ion transporter DMT1 and iron homeostasis by a ubiquitindependent mechanism involving Ndfips and WWP2. Blood. 2008;112(10):4268-4275.
37. Hathorn MK. The influence of hypoxia on iron absorption in the rat. Gastroenterology. 1971; 60(1):76-81.

38. Raja KB, Simpson RJ, Pippard MJ, Peters TJ. In vivo studies on the relationship between intestinal iron $(\mathrm{Fe} 3+)$ absorption, hypoxia and erythropoiesis in the mouse. $\mathrm{Br} \mathrm{J}$ Haematol. 1988;68(3):373-378

39. Nicolas G, Chauvet C, Viatte L, et al. The gene encoding the iron regulatory peptide hepcidin is regulated by anemia, hypoxia, and inflammation. J Clin Invest. 2002;110(7):1037-1044.

40. Piperno A, Galimberti S, Mariani R, et al HIGHCARE investigators. Modulation of hepcidin production during hypoxia-induced erythropoiesis in humans in vivo: data from the HIGHCARE project. Blood. 2011;117(10): 2953-2959.

41. Talbot NP, Lakhal S, Smith TG, et al. Regulation of hepcidin expression at high altitude. Blood. 2012;119(3):857-860.

42. Simpson RJ. Dietary iron levels and hypoxia independently affect iron absorption in mice. J Nutr. 1996;126(7):1858-1864.

43. Srai SK, Chung B, Marks J, et al. Erythropoietin regulates intestinal iron absorption in a rat model of chronic renal failure. Kidney Int. 2010;78(7): 660-667.

44. Frazer DM, Wilkins SJ, Becker EM, et al. A rapid decrease in the expression of DMT1 and Dcytb but not Ireg1 or hephaestin explains the mucosal block phenomenon of iron absorption. Gut. 2003; 52(3):340-346.

45. Kaelin WG Jr, Ratcliffe PJ. Oxygen sensing by metazoans: the central role of the HIF hydroxylase pathway. Mol Cell. 2008;30(4) 393-402.

46. Epstein AC, Gleadle JM, McNeill LA, et al. C. elegans EGL-9 and mammalian homologs define a family of dioxygenases that regulate HIF by prolyl hydroxylation. Cell. 2001;107(1):43-54.

47. Maxwell PH, Wiesener MS, Chang GW, et al. The tumour suppressor protein $\mathrm{VHL}$ targets hypoxia-inducible factors for oxygen-dependent proteolysis. Nature. 1999;399(6733):271-275.

48. Mahon PC, Hirota K, Semenza GL. FIH-1: a novel protein that interacts with HIF-1alpha and $\mathrm{VHL}$ to mediate repression of HIF-1 transcriptional activity. Genes Dev. 2001;15(20): 2675-2686

49. Dayan F, Roux D, Brahimi-Horn MC Pouyssegur J, Mazure NM. The oxygen sensor factor-inhibiting hypoxia-inducible factor-1 controls expression of distinct genes through the bifunctional transcriptional character of hypoxiainducible factor-1alpha. Cancer Res. 2006;66(7): 3688-3698

50. Wenger RH, Stiehl DP, Camenisch G. Integration of oxygen signaling at the consensus HRE. Sci STKE. 2005;2005(306):re12.

51. Peyssonnaux $C$, Nizet $V$, Johnson RS. Role of the hypoxia inducible factors HIF in iron metabolism. Cell Cycle. 2008;7(1):28-32.

52. Mastrogiannaki M, Matak $P$, Keith B, Simon MC, Vaulont S, Peyssonnaux C. HIF-2alpha, but not HIF-1alpha, promotes iron absorption in mice. J Clin Invest. 2009;119(5):1159-1166.

53. Shah YM, Matsubara T, Ito S, Yim SH, Gonzalez FJ. Intestinal hypoxia-inducible transcription factors are essential for iron absorption following iron deficiency. Cell Metab. 2009;9(2):152-164.

54. Mastrogiannaki $M$, Matak $P$, Delga $S$, Deschemin JC, Vaulont S, Peyssonnaux C. Deletion of HIF-2 $\alpha$ in the enterocytes decreases the severity of tissue iron loading in hepcidin knockout mice. Blood. 2012;119(2):587-590. 
55. Hu CJ, Sataur A, Wang L, Chen H, Simon MC The N-terminal transactivation domain confers target gene specificity of hypoxia-inducible factors HIF-1alpha and HIF-2alpha. Mol Biol Cell. 2007;18(11):4528-4542.

56. Matak P, Deschemin JC, Peyssonnaux C, Vaulont S. Lack of iron-related phenotype in Sp6 intestinal knockout mice. Blood Cells Mol Dis. 2011;47(1):46-49.

57. Parks SK, Chiche J, Pouyssegur J. pH control mechanisms of tumor survival and growth. $J \mathrm{Cell}$ Physiol. 2011;226(2):299-308.

58. Anderson ER, Xue X, Shah YM. Intestinal hypoxia-inducible factor-2alpha (HIF-2alpha) is critical for efficient erythropoiesis. J Biol Chem 2011;286(22):19533-19540.

59. Wiesener MS, Jürgensen JS, Rosenberger C, et al. Widespread hypoxia-inducible expression of HIF-2alpha in distinct cell populations of different organs. FASEB J. 2003;17(2):271-273.

60. Hentze MW, Muckenthaler MU, Galy B, Camaschella C. Two to tango: regulation of mammalian iron metabolism. Cell. 2010;142(1): 24-38.

61. Anderson CP, Shen M, Eisenstein RS, Leibold EA. Mammalian iron metabolism and its control by iron regulatory proteins. Biochim Biophys Acta. 2012;1823(9):1468-1483.

62. Vashisht AA, Zumbrennen KB, Huang $X$, et al. Control of iron homeostasis by an iron-regulated ubiquitin ligase. Science. 2009;326(5953): 718-721.

63. Zhang DL, Hughes RM, Ollivierre-Wilson $\mathrm{H}$, Ghosh MC, Rouault TA. A ferroportin transcript that lacks an iron-responsive element enables duodenal and erythroid precursor cells to evade translational repression. Cell Metab. 2009;9(5): 461-473.

64. Galy B, Ferring-Appel D, Kaden S, Gröne HJ, Hentze MW. Iron regulatory proteins are essential for intestinal function and control key iron absorption molecules in the duodenum. Cell Metab. 2008;7(1):79-85.

65. Galy B, Ferring D, Minana B, et al. Altered body iron distribution and microcytosis in mice deficient in iron regulatory protein 2 (IRP2). Blood. 2005;106(7):2580-2589.

66. Ferring-Appel D, Hentze MW, Galy B. Cellautonomous and systemic context-dependent functions of iron regulatory protein 2 in mammalian iron metabolism. Blood. 2009; 113(3):679-687.

67. Sanchez M, Galy B, Muckenthaler MU, Hentze MW. Iron-regulatory proteins limit hypoxiainducible factor-2alpha expression in iron deficiency. Nat Struct Mol Biol. 2007;14(5): 420-426.

68. Davis MR, Shawron KM, Rendina E, et al. Hypoxia inducible factor- $2 \alpha$ is translationally repressed in response to dietary iron deficiency in Sprague-Dawley rats. J Nutr. 2011;141(9): 1590-1596.

69. Anderson SA, Nizzi CP, Chang YI, et al. The IRP1-HIF-2 $\alpha$ axis coordinates iron and oxygen sensing with erythropoiesis and iron absorption. Cell Metab. 2013;17(2):282-290.

70. Ghosh MC, Zhang DL, Jeong SY, et al. Deletion of iron regulatory protein 1 causes polycythemia and pulmonary hypertension in mice through translational derepression of HIF2 $\alpha$. Cell Metab. 2013;17(2):271-281.

71. Galy B, Ferring-Appel D, Becker C, et al. Iron regulatory proteins control a mucosal block to intestinal iron absorption. Cell Rep. 2013;3(3): 844-857.

72. Recalcati S, Alberghini A, Campanella A, et al. Iron regulatory proteins 1 and 2 in human monocytes, macrophages and duodenum: expression and regulation in hereditary hemochromatosis and iron deficiency. Haematologica. 2006;91(3):303-310.

73. Luo QQ, Wang D, Yu MY, Zhu L. Effect of hypoxia on the expression of iron regulatory proteins 1 and the mechanisms involved. IUBMB Life. 2011;63(2):120-128.

74. Matak $\mathrm{P}$, Zumerle $\mathrm{S}$, Mastrogiannaki M, et al. Copper deficiency leads to anemia, duodenal hypoxia, upregulation of HIF-2 $\alpha$ and altered expression of iron absorption genes in mice. PLOS ONE. 2013;8(3):e59538.

75. Weiss $\mathrm{G}$. Iron metabolism in the anemia of chronic disease. Biochim Biophys Acta. 2009; 1790(7):682-693.

76. Nemeth E, Rivera S, Gabayan V, et al. IL-6 mediates hypoferremia of inflammation by inducing the synthesis of the iron regulatory hormone hepcidin. J Clin Invest. 2004;113(9): 1271-1276.

77. Rivera S, Ganz T. Animal models of anemia of inflammation. Semin Hematol. 2009;46(4): 351-357.

78. Rivera S, Liu L, Nemeth E, Gabayan V, Sorensen OE, Ganz T. Hepcidin excess induces the sequestration of iron and exacerbates tumorassociated anemia. Blood. 2005;105(4): 1797-1802.

79. Roy CN, Mak HH, Akpan I, Losyev G, Zurakowski D, Andrews NC. Hepcidin antimicrobial peptide transgenic mice exhibit features of the anemia of inflammation. Blood. 2007;109(9):4038-4044.

80. Rivera S, Nemeth E, Gabayan V, Lopez MA, Farshidi D, Ganz T. Synthetic hepcidin causes rapid dose-dependent hypoferremia and is concentrated in ferroportin-containing organs. Blood. 2005;106(6):2196-2199.

81. Johnson D, Bayele H, Johnston K, Tennant J, Srai SK, Sharp P. Tumour necrosis factor alpha regulates iron transport and transporter expression in human intestinal epithelial cells. FEBS Lett. 2004;573(1-3):195-201.

82. Laftah $\mathrm{AH}$, Sharma N, Brookes MJ, et al. Tumour necrosis factor alpha causes hypoferraemia and reduced intestinal iron absorption in mice. Biochem J. 2006;397(1):61-67.

83. Schubert TE, Bosserhoff AK, Peyssonaux C, et al. Hypoferraemia during the early inflammatory response is dependent on tumour necrosis factor activity in a murine model of protracted peritonitis. Mol Med Rep. 2012;6(4): 838-842.

84. Taylor CT, Colgan SP. Hypoxia and gastrointestinal disease. J Mol Med (Berl). 2007; 85(12):1295-1300.

85. Styś A, Galy B, Starzyński RR, et al. Iron regulatory protein 1 outcompetes iron regulatory protein 2 in regulating cellular iron homeostasis in response to nitric oxide. $J$ Biol Chem. 2011; 286(26):22846-22854.

86. Reynafarje C, Lozano R, Valdivieso J. The polycythemia of high altitudes: iron metabolism and related aspects. Blood. 1959;14(4):433-455

87. Beall CM, Cavalleri GL, Deng L, et al. Natural selection on EPAS1 (HIF2alpha) associated with low hemoglobin concentration in Tibetan highlanders. Proc Natl Acad Sci USA. 2010; 107(25):11459-11464

88. Simonson TS, Yang Y, Huff CD, et al. Genetic evidence for high-altitude adaptation in Tibet. Science. 2010;329(5987):72-75.

89. Ginzburg $Y$, Rivella S. $\beta$-thalassemia: a model for elucidating the dynamic regulation of ineffective erythropoiesis and iron metabolism. Blood. 2011;118(16):4321-4330.

90. Gardenghi S, Marongiu MF, Ramos P, et al. Ineffective erythropoiesis in beta-thalassemia is characterized by increased iron absorption mediated by down-regulation of hepcidin and upregulation of ferroportin. Blood. 2007;109(11): 5027-5035

91. Tanno T, Bhanu NV, Oneal PA, et al. High levels of GDF15 in thalassemia suppress expression of the iron regulatory protein hepcidin. Nat Med. 2007;13(9):1096-1101.

92. Babitt JL, Lin HY. The molecular pathogenesis of hereditary hemochromatosis. Semin Liver Dis. 2011;31(3):280-292

93. De Domenico I, Ward DM, Nemeth E, et al. The molecular basis of ferroportin-linked hemochromatosis. Proc Natl Acad Sci USA. 2005 102(25):8955-8960.

94. Rankin EB, Rha J, Selak MA, et al. Hypoxiainducible factor 2 regulates hepatic lipid metabolism. Mol Cell Biol. 2009;29(16): 4527-4538.

95. Levy JE, Montross LK, Andrews NC. Genes that modify the hemochromatosis phenotype in mice. J Clin Invest. 2000;105(9):1209-1216.

96. Constantine CC, Anderson GJ, Vulpe CD, et al A novel association between a SNP in CYBRD1 and serum ferritin levels in a cohort study of HFE hereditary haemochromatosis. $\mathrm{Br} J$ Haematol. 2009;147(1):140-149.

97. Zimmer M, Ebert BL, Neil C, et al. Smallmolecule inhibitors of HIF-2a translation link its 5'UTR iron-responsive element to oxygen sensing. Mol Cell. 2008;32(6):838-848.

98. Vachal P, Miao S, Pierce JM, et al. 1,3,8-Triazaspiro[4.5]decane-2,4-diones as efficacious pan-inhibitors of hypoxia-inducible factor prolyl hydroxylase 1-3 (HIF PHD1-3) for the treatment of anemia. J Med Chem. 2012; 55(7):2945-2959.

99. Denny WA. Giving anemia a boost with inhibitors of prolyl hydroxylase. J Med Chem. 2012;55(7): 2943-2944.

100. Kapitsinou PP, Liu Q, Unger TL, et al. Hepatic HIF-2 regulates erythropoietic responses to hypoxia in renal anemia. Blood. 2010;116(16): 3039-3048. 